\title{
Association Between Vitamin D and Glycaemic Parameters in a Multi-Ethnic Cohort of Postmenopausal Women with Type-2 Diabetes in Saudi Arabia
}

Shatha Alharazy ( $\sim$ smalharazy@kau.edu.sa )

King Abdulaziz University

\section{Eman Alissa}

King Abdulaziz University

Susan Lanham-New

University of Surrey

Muhammad Imran Naseer

King Abdulaziz University

Adeel G. Chaudhary

King Abdulaziz University

Margaret Denise Robertson

University of Surrey

\section{Research Article}

Keywords: Postmenopausal, Vitamin D, Deficiency, Type 2 Diabetes, Insulin Sensitivity, Insulin resistance, Saudi Arabia

Posted Date: March 6th, 2021

DOI: https://doi.org/10.21203/rs.3.rs-285226/v1

License: (9) This work is licensed under a Creative Commons Attribution 4.0 International License. Read Full License

Version of Record: A version of this preprint was published at BMC Endocrine Disorders on August 12th, 2021. See the published version at https://doi.org/10.1186/s12902-021-00825-3. 


\section{Abstract}

Background: The relationship between Vitamin D (VitD) with insulin sensitivity and secretion in Type-2 diabetes (T2D) has shown to be different amongst different ethnic populations. In Saudi Arabia, where both T2D and VitD deficiency are highly prevalent health concerns, little is known about the relationship between VitD, insulin sensitivity, resistance and the relative importance of ethnicity. Our aim in this study is to investigate influence of ethnicity on VitD association with glycaemic profile primarily and to measures of obesity secondarily, among multiethnic postmenopausal women with T2DM in Saudi Arabia.

Methods: A cross-sectional study was conducted at King Fahad Medical Research Center, King Abdulaziz University, Jeddah, Saudi Arabia. Postmenopausal females ( $n=173$, age $\geq 50$ years) with T2D were randomly selected in this study. Anthropometric measures and fasting blood samples were obtained for all study participants. Several biochemical parameters were measured including 25-hydroxyvitamin D (25(OH)D), glycosylated hemoglobin ( $\mathrm{HbA1c}$ ), insulin, glucose and c-peptide. Surrogate markers for insulin resistance were calculated using Homeostasis Model Assessment 2 for insulin resistance and beta cell activity (HOMA2-IR, HOMA2- $\beta$ ).

Results: Overall, 25(OH)D was inversely associated with fasting glucose $(r=-0.165, P=0.037)$, insulin ( $r=-0.184, P=0.02)$, C-peptide ( $r=-0.19, P=0.015)$ and HOMA2- IR C-peptide $(r=-0.23, P=0.004)$. Additionally, serum $25(\mathrm{OH}) D$ showed an overall a negative correlation with body weight $(r=-0.173 \mathrm{P}=0.028)$, waist and hip circumferences $(r=-0.167, P=0.033 ; r=-0.22, P=0.004$ respectively) but not with body mass index (BMI) or waist hip ration (WHR).

In the white ethnic group but not in black or Asian population groups, $25(\mathrm{OH}) \mathrm{D}$ level was associated with only serum fasting C-peptide and HOMA2-IR C-peptide and BMI $(P<0.05)$.

Conclusions: Insulin resistance and obesity are associated with VitD status in T2D in this cohort. Our findings also suggest that these VitD associations in women from white ethnic background are different than in those from black/Asian ethnic backgrounds. Whether VitD supplements are able to improve degree of obesity and insulin sensitivity should be further investigated in different ethnic population groups.

\section{Background}

Vitamin D (VitD) has a pivotal role in the regulation of calcium (Ca) concentrations in blood through its influence on intestinal absorption and bone metabolism and through its interaction with calciotropic hormones [1]. The influence of VitD on extra-skeletal tissue is gaining increasing prominence in the literature thought to contribute to insulin resistance, pathology of pancreatic $\beta$-cell and systemic inflammation and ultimately Type 2 diabetes (T2D) risk [2-7]. It is proposed that VitD can influence the progression and control of T2D either directly by binding to its own receptor (VitD receptor) on $\beta$-cells of the pancreas or indirectly by regulating extracellular $\mathrm{Ca}$ or $\mathrm{Ca}$ influx to pancreatic $\beta$-cells $[8,9]$. 
VitD deficiency/insufficiency, which is assessed by circulating blood 25-hydroxyvitamin D 25(OH)D concentration, is one of the most globally widespread health concerns among postmenopausal women [10] and has been suspected as a risk factor for T2D in Europeans, African-Americans and south Asians [4-7]. It has also been reported that an inverse relationship exists between VitD status and risk of T2D and metabolic syndrome [11].

In several observational studies, VitD deficiency has been linked to insulin sensitivity and secretion which are both might be impaired in T2D; however the role of ethnicity has not been fully examined $[2,12,13]$. A large cross-sectional study [14] in the US revealed that the Homeostatic Model Assessment of Insulin Resistance (HOMA-IR) and $\beta$-cell secretion $(\mathrm{HOMA} \% \beta)$ showed no association with serum $25(\mathrm{OH}) \mathrm{D}$ level in non-Hispanic black individuals. However, the same study revealed a correlation between 25(OH)D levels and HOMA-IR in non-Hispanic whites and Mexican Americans. This finding can be interpreted as due to a lower responsiveness to VitD and parathyroid hormone (PTH) in blacks in comparison to whites [14].

Saudi Arabia has a multi-ethnic population and both T2D and VitD deficiency are highly prevalent and of widespread concerns $[15,16]$.

There are few data in the literature from Saudi Arabia concerning the association/relationship between VitD, insulin sensitivity and resistance with consideration of ethnicity. The aim of this study therefore was to investigate the effects of ethnicity on VitD (25(OH)D) associations with insulin sensitivity, diabetic control and measures of obesity in postmenopausal women in Saudi Arabia with T2D; to target prospectively the ethnic group with stronger VitD associations for VitD dosing treatment.

\section{Methods}

\section{Study design and recruitment}

This cross-sectional study was conducted on 173 postmenopausal women with T2D, aged between 50 and 87 years, living in the western region of Saudi Arabia (Jeddah). We assessed VitD status (25(OH)D) in the participants and its association with: (1) glycaemic parameters (HbA1c, fasting glucose, fasting insulin, fasting $\mathrm{C}$-peptide and insulin sensitivity indices and high sensitivity C-reactive protein (hsCRP)); (2) bone related parameters (intact PTH, Ca, albumin, phosphorus (PO4) and magnesium (Mg)); (3) anthropometric measures (weight, height, waist hip ratio (WHR) and BMI); (4) lifestyle factors (physical activity, smoking, dietary VitD intake, veiling and sun exposure); (5) Socio-demographic factors including skin tone and ethnicity.

Subjects for this study were sequentially recruited from seven primary health care centers (PHCCs) distributed in Jeddah (a PHCC from each of the seven geographical sectors of Jeddah area to guarantee that the average health status of the participating women will represent a randomly selected adult population). A multi-stage sampling technique was implemented. In stage 1, one PHCC was chosen from each of the seven sectors of the Jeddah area. In stage 2 , random selection of samples was conducted 
from the selected PHCCs to select female files of the registered population. In stage 3 , all women in the selected age group ( $\geq 50$ years) among selected files were contacted for possible recruitment to the study based on the predefined criteria of inclusion. The number of women randomly selected from each center was proportionally identified according to the number of the registered women in each center. Subjects willing to participate in this study were referred to a clinic at the Centre of Excellence for Osteoporosis Research (CEOR) in King Fahd Medical Research Centre (KFMRC), King Abdulaziz University (KAU), Jeddah. Each participant provided written informed consent relating to participation in this study. Following the ethical standards in Declaration of Helsinki, ethical approval of this study was obtained from the Research Ethics Committee, the Faculty of Medicine, KAU (ref no.179 - 16, Oct/2017).

The recruitment and selection of patients was based on specific inclusion and exclusion criteria. Inclusion criteria included postmenopausal women: Last menstrual period (LMP) $\geq 1$ year and follicular stimulating hormone $(\mathrm{FSH})>15 \mathrm{IU} / \mathrm{L}$ ), previously diagnosed with $\mathrm{T} 2 \mathrm{D}$ according to the criteria of the American Diabetes Association ( $\mathrm{HbA} 1 \mathrm{c} \geq 48 \mathrm{mmol} / \mathrm{mol}$ or fasting plasma glucose $\geq 7 \mathrm{mmol} / \mathrm{L}$ ) [17]. Women with history of chronic liver or renal disease, cancer, malabsorption syndrome, rheumatoid arthritis, hyperthyroidism, other endocrinal disorders that might affect bone (e.g. Hyperparathyroidism) or history of intake of medications with possible effects on VitD (e.g. VitD supplements, glucocorticoids and anticonvulsants) were excluded from the study. Following multiple stages of exclusion (Fig. 1), a sample size of 173 was included in this study.

Initially, all participants answered a questionnaire (completed by the researcher), which requested information including socio-demographic factors, dietary VitD intake (semi-quantitative Food Frequency Questionnaire (SFFQ) [18]), lifestyle history including smoking habits and physical activity, medical history, menstrual history and drug history. Each participant underwent anthropometric and blood pressure measurements.

Skin tone was recorded for each participant based on the Fitzpatrick skin tone classification [14]. Duration (number of hours) of weekly exposure to outdoor sunlight in the last month was noted in the participants' questionnaires as well as the use of sunscreen. Due to cultural or religious reasons, most women in Saudi Arabia, especially the elderly, wear a veil and cape. Women participating in the study who cover their head and body, with face and hands exposed were considered as partially covered, while participating women covering their whole body and face, with only the eyes and hands exposed were considered as totally covered.

VitD daily intake from food was estimated using a semi-quantitative Food Frequency Questionnaire (SFFQ). The SFFQ used in the study was adapted from a validated SFFQ in Saudi Arabia [18]. Items included the most commonly VitD rich food consumed in the region; salmon, tuna, sardines, milk, laban (buttermilk), yogurt, egg and beef liver. The frequency of this food intake was expressed as number of servings per day/week/month. The daily VitD intake in IU was then calculated and compared to their estimated average requirement (EAR) (600-800 IU/day based on the IOM recommendation for women aged $50 \mathrm{y}$ and over [19]). 


\section{Serum measurements of 25(OH)D and other hormones}

Serum 25(OH)D and intact PTH levels were measured by direct competitive chemiluminescence immunoassay (CLIA), using a LIASON auto-analyzer (DiaSorin Inc, Stillwater, MN, USA). The intra and inter-assay coefficient of variations (CV) of serum samples were $<8 \%$. VitD deficiency was defined based on Institute of Medicine (IOM) guidelines [19] as the 25(OH) D level below $12 \mathrm{ng} / \mathrm{ml}(<30 \mathrm{nmol} / \mathrm{l})$ and VitD insufficiency as the $25(\mathrm{OH}) \mathrm{D}$ level of $12-19 \mathrm{ng} / \mathrm{ml}(30-49 \mathrm{nmol} / \mathrm{l})$, and VitD sufficiency between $20-50 \mathrm{ng} / \mathrm{ml}(50-125 \mathrm{nmol} / \mathrm{L})$. FSH and Thyroid function test (TFT) including thyroid-Stimulating Hormone (TSH), free thyroxin (T3) and free triiodothyronine (T4) were measured in serum by immunoassays, using VITROS ECiQ (Ortho-Clinical Diagnostics Inc., Rochester, NY, USA) to exclude any women with hyperthyroidism or not postmenopausal.

\section{Serum measurements of liver enzymes, renal function, high-sensitivity C-reactive protein, lipid and bone profile}

Liver enzymes (including Aspartate Aminotransferase (AST), Alanine Aminotransferase (ALT), and Alkaline Phosphatase (ALP)), creatinine, total cholesterol, direct High Density Lipoprotein (HDL), triglycerides, Low Density Lipoprotein (LDL), Very Low Density Lipoprotein (VLDL) albumin, Ca, PO4 and $\mathrm{Mg}$ ) were all measured in serum by reflectance spectrophotometry, employing the colorimetric method using a VITROS 250 Clinical Chemistry Auto-analyzer (Ortho-Clinical Diagnostics Inc., Rochester, NY, USA). The intra and inter-assay CV of serum samples were $4.1 \%$ and $4.5 \%$ respectively. Low Density Lipoprotein (LDL) concentrations in serum were directly calculated by the analyzer, based on standardized calculations (Friedewald equation [20]) dependent on the level of total cholesterol, direct $\mathrm{HDL}$ and triglyceride measured by the same analyzer. Very Low Density Lipoprotein (VLDL) serum levels were estimated by dividing the triglyceride by 2.2. Subjects with high liver enzymes were excluded (the normal clinical level of serum being AST $₫ 45 \mathrm{U} / \mathrm{L} ; \mathrm{ALT} \otimes 50 \mathrm{U} / \mathrm{L}$ and ALP between 80 and $280 \mathrm{U} / \mathrm{L}$ ). Samples with creatinine levels higher than normal were excluded (i.e. a normal level of serum creatinine in females $\otimes 105 \mu \mathrm{mol} / \mathrm{L}$ ).

Hs-CRP was measured in serum by immunoassay, using a VITROS 5,1 FS chemistry auto-analyzer (OrthoClinical Diagnostics Inc., Rochester, NY, USA). The intra-assay and inter-assay CV of serum samples were $3.5 \%$ and $4 \%$ respectively.

\section{Measurements of glycaemic control parameters}

Glycosylated hemoglobin (HbA1c) was determined using a VITROS 5,1 FS chemistry auto-analyzer (Ortho-Clinical Diagnostics Inc., Rochester, NY, USA). Fasting glucose in serum was measured by means of a colorimetric method, using a VITROS 250 Clinical Chemistry Auto-analyzer (Ortho-Clinical Diagnostics Inc., Rochester, NY, USA). The intra and inter-assay CV for HbA1c and fasting glucose samples were both $<5 \%$. Insulin and c-peptide (a consequent product produced when insulin is secreted) were measured in serum by a sandwich CLIA using a LIAISON autoanalyzer (DiaSorin Inc, Stillwater, MN, USA). The intra and inter-assay CV for insulin and C-peptide serum samples were both $<6 \%$. Fasting 
insulin and Homeostasis Model Assessment 2 (HOMA2) [21] were measured for all women, with the exception of those on insulin therapy, due to the influence of insulin intake on these measures.

HOMA2 was used to estimate insulin resistance and $\beta$-cell function. HOMA2 indices [22] (HOMA2-IR and HOMA2- $\% \beta$ ) were calculated from fasting glucose, fasting insulin and fasting c-peptide in a steady-state condition (fasting glucose: $3-25 \mathrm{mmol} / \mathrm{L}$, fasting insulin: $2.88-43.16 \mathrm{mlU} / \mathrm{L}$ and fasting c-peptide: $0.6-$ $10.5 \mu \mathrm{U} / \mathrm{ml}$ ) using an updated computer HOMA calculator software (version 2.2.3) issued by University of Oxford Diabetes Trials Unit, available at https://www.dtu.ox.ac.uk/homacalculator/ .

\section{Statistical analysis}

The statistical analysis was performed using SPSS program (v.20 SPSS Chicago Inc). Normality of data was tested by Kolmogorov-Smirnov test. All numerical parametric results were expressed as means $\pm S D$, while numerical non-parametric results were presented as median (IQR). Descriptive results were expressed as a percentage of the total sample number. Correlations between different parameters were obtained using Pearson correlation for normally distributed data and Spearman correlation for nonnormally distributed data. The non-parametric test, Kruskal-Wallis $\mathrm{H}$ test, was used based on non-normal distribution of data to compare between groups. A probability value $\leq 0.05$ was considered statistically significant. Multiple linear regression analysis (stepwise) was used for independent variables that showed significant correlations at the bivariate level $(P \leq 0.05)$ to determine independent predictors of the dependent variable.

\section{Results}

Participants' general characteristics are summarized in (Table 1). 
Table 1

General characteristics of the participating women

\begin{tabular}{|c|c|}
\hline \multirow[t]{2}{*}{ Variables } & $(N=173)$ \\
\hline & Results \\
\hline - Age (years) & $59.6 \pm 6.8$ \\
\hline - Age at menopause (years) & $49.7 \pm 4.2$ \\
\hline - Years since menopause & $9.8 \pm 7.2$ \\
\hline - Age at T2DM diagnosis (years) & $46.7 \pm 9.3$ \\
\hline - Years since T2DM & $12(6-20)$ \\
\hline \multicolumn{2}{|l|}{ - DM therapy mode } \\
\hline Diet & $5(3 \%)$ \\
\hline $\mathrm{OHD}$ & $91(53 \%)$ \\
\hline Diet + OHD & $3(2 \%)$ \\
\hline Insulin & $15(9 \%)$ \\
\hline Insulin + OHD & $59(34 \%)$ \\
\hline - Use of statin therapy & $84(49 \%)$ \\
\hline \multicolumn{2}{|c|}{ - Hypertensive (according to medical records) } \\
\hline Yes & $125(72 \%)$ \\
\hline No & $48(28 \%)$ \\
\hline • SBP (mmHg) & $144 \pm 23$ \\
\hline • DBP (mmHg) & $82(76-90)$ \\
\hline \multicolumn{2}{|l|}{ - Marital status } \\
\hline Single & $1(1 \%)$ \\
\hline Married & $113(65 \%)$ \\
\hline Divorced & $10(6 \%)$ \\
\hline Widow & $49(28 \%)$ \\
\hline \multicolumn{2}{|l|}{ - Education } \\
\hline Illiterate & $73(42 \%)$ \\
\hline Elementary & $36(21 \%)$ \\
\hline Intermediate & $29(17 \%)$ \\
\hline
\end{tabular}




\begin{tabular}{|c|c|}
\hline \multirow[t]{2}{*}{ Variables } & $(N=173)$ \\
\hline & Results \\
\hline Secondary & $25(14 \%)$ \\
\hline University & $10(6 \%)$ \\
\hline Postgraduate & $0(0 \%)$ \\
\hline \multicolumn{2}{|l|}{ - Occupation } \\
\hline Housewife & $160(93 \%)$ \\
\hline Governmental employed & $0(0 \%)$ \\
\hline Privately employed & $4(2 \%)$ \\
\hline Self-employed & $0(0 \%)$ \\
\hline Retired & $9(5 \%)$ \\
\hline \multicolumn{2}{|l|}{ • Ethnicity } \\
\hline White (Arabic) & $126(73 \%)$ \\
\hline Black (African) & $30(17 \%)$ \\
\hline South Asian (Pakistani) & $17(10 \%)$ \\
\hline \multicolumn{2}{|l|}{ • Skin tone (Fitzpatrick)* } \\
\hline Type $\otimes$ (light, pale white) & $0(0 \%)$ \\
\hline Type $\otimes$ (white, fair) & $24(14 \%)$ \\
\hline Type $₫$ (medium white to olive) & $68(39 \%)$ \\
\hline 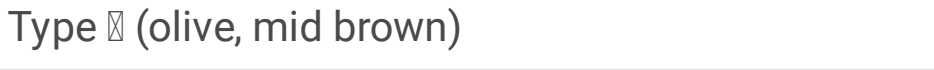 & $50(29 \%)$ \\
\hline Type $\otimes$ (brown, dark brown) & $31(18 \%)$ \\
\hline Type $\otimes$ (very dark brown, black) & $0(0 \%)$ \\
\hline \multicolumn{2}{|l|}{ - Sun exposure } \\
\hline$<1 \mathrm{hr} /$ week & $85(49 \%)$ \\
\hline 1-2 hr/week & $48(28 \%)$ \\
\hline 2-3 hr/week & $21(12 \%)$ \\
\hline$>3 \mathrm{hr} /$ week & $19(11 \%)$ \\
\hline \multicolumn{2}{|l|}{ - Veiling type } \\
\hline Totally covered (use of niqab: eyes exposed only) & $125(72 \%)$ \\
\hline
\end{tabular}




\begin{tabular}{|ll|}
\hline Variables & $\begin{array}{l}\mathbf{N}=173) \\
\text { Results }\end{array}$ \\
\hline Partially covered (face exposed) & $48(28 \%)$ \\
\hline • Use of sunscreen & $0(0 \%)$ \\
\hline • Subjects consuming dietary VitD above EAR** & $0(0 \%)$ \\
\hline • Physical activity & \\
\hline Yes & $53(31 \%)$ \\
\hline No & $120(69 \%)$ \\
\hline - Smoking & $3(2 \%)$ \\
\hline Yes & $170(98 \%)$ \\
\hline No & $4.2 \pm 1.3$ \\
\hline S Serum total cholesterol (mmol/L) & $1.4(0.99-2.2)$ \\
\hline - Serum triglyceride (mmol/L) & $1.0(0.8-1.3)$ \\
\hline - Serum HDL-C (mmol/L) & $2.15(1.7-3.0)$ \\
\hline - Serum LDL-C (mmol/L) & $0.62(0.45-1.0)$ \\
\hline - Serum VLDL-C (mmol/L) & $5.4(2.8-9.9)$ \\
\hline - Serum hs-CRP (mg/L) & \\
\hline
\end{tabular}

Table: 1 . Showed the numerical data presented as mean \pm SD if normally distributed and as median (IQR) if non-normally distributed. Descriptive data are presented as n (\%).T2DM is type-2 Diabetes Mellitus. OHD is Oral Hypoglycemic Drugs. BMI represents Body Mass Index; WHR: Waist Hip Ratio; SBP: Systolic Blood pressure; and DBP: Diastolic Blood Pressure *Fitzpatrick scale [53]. EAR is estimated average requirement. ** EAR for women aged 50 y and over based on IOM recommendation (600-800 IU/day) [19]. 25(OH)D is 25-hydroxyvitamin D; PTH is Parathyroid Hormone; Ca is Calcium; PO4 is phosphate; and Mg is Magnesium. HDL-C is high lipoprotein cholesterol; LDL-C is low density lipoprotein cholesterol; VLDL-C is very low density lipoprotein cholesterol; and hs-CR is high sensitive C-reactive protein.

Serum 25(OH)D levels and daily dietary VitD intake results in all participating women and in subclassified ethnic groups are shown in (Table 2); showing overall serum 25(OH)D mean ( \pm SD) of $14.2 \pm$ $9.2 \mathrm{ng} / \mathrm{ml}$ and non-significant differences in median of serum 25(OH) D levels and dietary daily VitD intake between ethnic groups. 
Table 2

Serum 25(OH)D levels and dietary VitD daily intake among the participants as classified by ethnicity.

\begin{tabular}{|c|c|c|c|c|}
\hline Ethnicity & $\begin{array}{l}25(\mathrm{OH}) \mathrm{D} \\
(\mathrm{ng} / \mathrm{ml})\end{array}$ & $P$ & Dietary VitD intake (IU/day) & $P$ \\
\hline Overall $(n=173)$ & $14.2 \pm 9.2$ & & $110(53.5-180)$ & \\
\hline White-Arabic $(n=126)$ & $13.1(7.6-19.2)$ & \multirow[t]{3}{*}{0.70} & $110(62-168)$ & \multirow[t]{3}{*}{0.38} \\
\hline Black-African $(n=30)$ & $10.8(8.2-17.3)$ & & $114(73-218)$ & \\
\hline Asian-Pakistani $(\mathrm{n}=17)$ & $12(6-17.6)$ & & $100(60-176)$ & \\
\hline
\end{tabular}

Table: 2. Showed a numerical data presented as mean \pm SD or median (IQR). 25(OH)D is 25-

hydroxyvitamin D. Differences in VitD between different ethnic groups were tested by Kruskal-Wallis $\mathrm{H}$ test.

According to IOM [19] guidelines for VitD status classification, 47\% were VitD deficient, $31 \%$ were VitD insufficient, and $22 \%$ demonstrated optimal levels of VitD

In the complete cohort, the relationship between serum $25(\mathrm{OH}) \mathrm{D}$ level showed an inverse association with body weight $(P=0.028)$, waist and hip circumferences $(P=0.033, P=0.004$ respectively). Conversely, $\mathrm{BMI}, \mathrm{WHR}$, blood pressure did not show any association with total $25(\mathrm{OH}) \mathrm{D}$ (Table 2). When the relationships were investigated in each ethnic group independently, no statistical significant correlation was found except for BMI, which was positively correlated with $25(\mathrm{OH}) \mathrm{D}$ in white postmenopausal women $(r=-0.250, P=0.009$, Pearson correlation, 2-tailed).

The correlation between 25(OH)D and bone related parameters were non-significant except for serum intact PTH which showed an inverse relationship with 25(OH)D $(p<0.0001)($ Table 3$)$. No independent effect of ethnicity was found. 
Table 3

The serum 25(OH)D correlation with anthropometric measures and bone related parameters in whole group.

\begin{tabular}{|c|c|c|c|}
\hline \multirow[t]{2}{*}{ Variable } & \multirow{2}{*}{$\begin{array}{l}\text { Results } \\
(N=173)\end{array}$} & \multicolumn{2}{|c|}{ Correlation with $25(\mathrm{OH}) \mathrm{D}$} \\
\hline & & $\mathbf{r}$ & $\mathbf{P}$ \\
\hline Weight (kg) & $79.3 \pm 18$ & $-0.173^{*}$ & $0.028 *$ \\
\hline Height (cm) & $154.7 \pm 6$ & -0.020 & $>0.1$ \\
\hline BMI $\left(\mathrm{kg} / \mathrm{m}^{2}\right)$ & $49.5(43.3-58)$ & -0.120 & $>0.1$ \\
\hline Waist circumference (cm) & $100.2 \pm 12.7$ & $-0.167 *$ & $0.033^{*}$ \\
\hline Hip circumference (cm) & $113.5 \pm 13.4$ & $-0.220 *$ & $0.004^{*}$ \\
\hline WHR & $0.9 \pm 0.06$ & 0.086 & $>0.1$ \\
\hline Serum Intact PTH (pg/ml) & $47.9(33.3-61.9)$ & $-0.340 *$ & $<0.0001 *$ \\
\hline Serum Ca (mmol/L) & $2.25(2.07-2.42)$ & 0.009 & $>0.1$ \\
\hline Serum $\mathrm{PO}_{4}(\mathrm{mmol} / \mathrm{L})$ & $1.19 \pm 0.2$ & -0.060 & $>0.1$ \\
\hline Serum $\mathrm{Mg}(\mathrm{mmol} / \mathrm{L})$ & $0.7(0.6-0.8)$ & -0.110 & $>0.1$ \\
\hline
\end{tabular}

Table: 3. Results are presented as mean \pm SD or median (IQR). ${ }^{*}$ Significant correlation $(p<0.05)$. $\checkmark$ Pearson correlation (2-tailed). The rest of correlations are Spearman correlations (2-tailed). PTH: parathyroid hormone, Ca: calcium, PO4: phosphorus, Mg: magnesium.

When correlations were assessed between serum 25(OH)D and the glycaemic control parameters, a significant negative correlation was found between 25(OH)D and: fasting glucose $(P=0.037)$, fasting insulin ( $P=0.02)$ fasting $C$-peptide $(P=0.015)$, HOMA2- IR C-peptide $(P=0.004)$ (Fig. 2$)$. The correlations between $25(\mathrm{OH})$ and the remaining glycaemic control parameters (including HbA1c, HOMA2- IR insulin, HOMA2-\% $\beta$ ) were not significant.

After dividing the group according to ethnicity, 25(OH)D was associated with serum fasting C-peptide and HOMA2-IR C-peptide in white group only, while it was not associated with any parameters in either black and Asian groups (Table 4). Additionally, 25(OH)D levels did not show any significant correlation with and skin tones, sun exposure, dietary VitD intake, veiling type, age, duration of diabetes and menopause, ethnicity, presence of hypertension, DM treatment, BMI classes, smoking, marital status, occupation or education (data not shown). 
Table 4

Correlations between 25(OH) D and glycaemic parameters among different ethnic groups of the study participants.

\begin{tabular}{|c|c|c|c|c|c|c|c|}
\hline \multirow[t]{2}{*}{ Variable } & \multirow{2}{*}{$\begin{array}{l}\text { Results } \\
(\mathrm{N}=173)\end{array}$} & \multicolumn{2}{|c|}{ White $(n=126)$} & \multicolumn{2}{|c|}{ Black $(n=30)$} & \multicolumn{2}{|c|}{ Asian $(n=17)$} \\
\hline & & $\mathbf{r}$ & $\mathbf{P}$ & $\mathbf{r}$ & $\mathbf{P}$ & $\mathbf{r}$ & $\mathbf{P}$ \\
\hline Fasting insulin (pmol/L) & $93.05 \pm 72.9$ & -0.14 & $>0.1$ & -0.27 & 0.27 & -0.24 & $>0.1$ \\
\hline Fasting c-peptide (nmol/L) & $0.98 \pm 0.51$ & $-0.23^{*}$ & $0.012^{*}$ & -0.03 & 0.86 & -0.21 & $>0.1$ \\
\hline Fasting glucose (mmol/L) & $7.4(5.6-10.2)$ & -0.17 & 0.065 & -0.13 & 0.57 & 0.075 & $>0.1$ \\
\hline $\mathrm{HbA1c}(\mathrm{mmol} / \mathrm{mol})$ & $64 \pm 864 \pm 8$ & -0.03 & $>0.1$ & -0.21 & 0.29 & 0.003 & $>0.1$ \\
\hline HOMA2-IR insulin & $2.69 \pm 1.54$ & 0.20 & $>0.1$ & -0.23 & 0.35 & -0.20 & $>0.1$ \\
\hline HOMA2-\% $\beta$ insulin & $79.9(46.1-136.9)$ & 0.10 & $>0.1$ & 0.045 & 0.86 & -0.10 & $>0.1$ \\
\hline HOMA2-IR C-peptide & $2.7 \pm 8.56$ & $-0.25^{*}$ & $0.009 *$ & -0.23 & 0.27 & -0.26 & $>0.1$ \\
\hline HOMA2-\%ß C-peptide & $69.5(35.3-102.6)$ & 0.066 & $>0.1$ & 0.12 & 0.57 & -0.23 & $>0.1$ \\
\hline
\end{tabular}

Table: 4. *Significant correlation $(p<0.05)$. Correlations in white group are Pearson correlation (2tailed). Correlations in black and Asian group are Spearman correlations (2-tailed). $\$$ Measured in subjects not taking exogenous insulin, total $(n=99)$ : white $(n=68)$, black $(n=21)$ and Asian $(n=10)$. HOMA2-IR is homeostatic assessment 2 for insulin resistance. HOMA2-\% $\beta$ is homeostatic assessment 2 for $\beta$-cell function; HOMA2-IR/\% $\beta$ C-peptide was calculated using fasting glucose and C-peptide; HOMA2$\mathrm{IR} / \% \beta$ insulin was calculated using fasting glucose and fasting insulin.

\section{Discussion}

Percentages of VitD deficiency between 40 to $100 \%$ were identified in previous studies in elderly US and European cohorts [23-34]. In the Middle East including Saudi Arabia, 25(OH)D deficiency has been observed previously despite the abundance of sunlight, with almost half of the study subjects (47\%) having VitD deficiency and 31\% VitD insufficiency. This high prevalence of VitD deficiency or insufficiency found in our study subjects was expected due to several factors influencing negatively on VitD status including lack of adequate sunlight exposure (specifically among residents of Saudi Arabia due to veiling and extreme hot weather) and inadequate dietary VitD intake.

The current study is the first to investigate insulin resistance and sensitivity (including HOMA-2) in multiethnic groups in Saudi Arabia (Jeddah). VitD in this study was found to be significantly correlated ( $p<$ 0.05) with fasting insulin, fasting glucose, fasting C-peptide and insulin resistance indices (HOMA2-IR Cpeptide).This finding was consistent with what was reported by Forouhi et al [35], Hahn et al [36] and Weiler et al [37], Weiler et al [37], Dutta et al [38]. These associations between VitD and glycaemic parameters in our study can be attributed to the biological mechanism suggesting that VitD has a direct effect on pancreatic $\beta$-cell by binding to VDR or its indirect effect through its role in regulation of 
extracellular $\mathrm{Ca}$ and $\mathrm{Ca}$ flux into pancreatic $\beta$-cell [39]. Our results show that ethnicity can modify the associations between VitD and glycaemic markers as $25(\mathrm{OH}) \mathrm{D}$ was associated with serum fasting $\mathrm{C}$ peptide and HOMA2-IR C-peptide in white group $(n=126)$, but not associated with any diabetic parameter of the study in the black $(n=30)$ and Asian $(n=17)$ groups. This finding confirms findings from a large cross-sectional US study in non-Hispanic whites and blacks carried by Scragg et al, where 25(OH)D was associated with HOMA-IR in whites but not in blacks [14]. The mechanism underlying this absence of an association between $25(\mathrm{OH}) \mathrm{D}$ and insulin resistance in blacks is unclear. This observed differences in VitD relationship with T2D between blacks and whites might be due to the variation in the threshold which VitD take effect in different ethnicities and the possible decreased responsiveness to VitD and PTH in blacks [14]. Further studies are needed to clarify the ethnic discrepancy in VitD action, which could only be achieved using a supplementation protocol, thus providing novel insight into potential preventive mechanisms linked to VitD for this specific group.

Our data failed to show any association between VitD and glycemic control (HbA1c) which was in line with what has been reported [40,41]. Moreover, a meta-analysis of fifteen dietary intervention trials demonstrated that, in type 1 and 2 diabetic patients (or patients with impaired glucose intolerance), VitD had no impact on improving HbA1c [42]. However, the situation is far from clear with several studies finding an association with $\mathrm{HbA1c}$, including a cohort study from Saudi Arabia in 1000 patients with type 1 and 2 diabetes which demonstrated an inverse correlation [43-46]. Diabetes is a heterogenous disease with multiple treatment modalities and so discrepancies between studies are to be expected, a problem which can only be addressed by more defined and larger populations within studies.

In the present study, we explored VitD association with measures of obesity in T2D and we found that VitD was related inversely with weight, waist and hip circumferences which is not unanticipated as obesity has an adverse effect on VitD status and is associated with decrease in circulating 25(OH)D due to storage of 25(OH)D in adipose tissue [47,48]. However, VitD was not related neither to BMI or WHR (conventional measures of overall obesity and central obesity respectively), which is in controversy with what some other studies have observed $[47,49,50]$. However, when we considered ethnicity in investigating the relationship between $25(\mathrm{OH}) \mathrm{D}$ and anthropometric measure, we found that $25(\mathrm{OH}) \mathrm{D}$ was associated with $\mathrm{BMI}$ in white women. In comparison, 25(OH)D was not associated with anthropometric measures in the other two ethnic groups (black and Asian). These finding are in agreement with findings of other studies that has shown that ethnicity might modify the relationship between adiposity (including BMI and WHR) and serum 25(OH)D, as in prior studies either lack of association was observed between these variables in single multi-ethnic study groups or different associations was found between groups of different ethnicities as the case in our study where participants were from different ethnic origins residing in city of Jeddah, the most Saudi Arabian city combining residents from disperse races $[14,51,52]$. These observations question whether VitD supplementation effect on obesity as well as insulin resistance will be the same among individuals from different ethnicities. This also highlights the urge to investigate in the future the anthropometric and glycaemic measures response to VitD supplementation in multiple ethnicities, and therefore might 
subsequently suggests ethnically personalized VitD recommendations against obesity or insulin resistance.

Overall, there is an urge for postmenopausal women with T2DM living in Saudi Arabia to elevate their VitD levels (which can be approached by modest and priceless ways including VitD supplementation and sufficient sunlight exposure). In addition, further studies are required to explore VitD protective mechanism against T2D and measures of adiposity in various ethnic cohorts, to understand observed disparity of VitD impact on T2D and adiposity between different ethnicities and to find out if insulin sensitivity or resistance would respond to VitD treatment in individuals from white, black and Asian ethnic backgrounds. In addition, determination of a cut-off level of 25(OH)D for improving insulin resistance will be considered in the future study.

The present study has several limitations that have to be taken into account or consideration when interpreting the results. In the current study, sample sizes of subcategorized black and Asian ethnic groups were inadequate and would need to be increased in order to confirm these findings related to ethnicity. Another limitation is that this study is cross-sectional in nature. Therefore, causality or temporal VitD associations in diabetes cannot be confirmed. An additional limitation is not using the gold standard method for insulin resistance assessment which is the Hyperinsulinemic Euglycemic Clamp method due to its complexity. Furthermore, variations in diabetic regimens, duration of T2D and degree of glycaemic control among participating women might contribute to the VitD relationship with glycaemic control parameters.

\section{Conclusion}

Our concluding remarks are as follows: VitD deficiency (serum $25(\mathrm{OH}) \mathrm{D}<12 \mathrm{ng} / \mathrm{ml}$ ) is highly prevalent among postmenopausal women with T2D. Our findings confirm the inverse VitD relationship with some measures of obesity and insulin sensitivity in T2D, however this association was only observed in white subjects but not in those from black or Asian origin. Further studies are required to understand the underlying mechanism responsible for ethnic variation in VitD relationship with T2D and obesity and to explore and compare VitD supplementation effect on insulin sensitivity and resistance in black, and white and Asian ethnic groups.

\section{Abbreviations}

25(OH)D: 25-hydoxyvitamin D

ALP: alkaline phosphatase

ALT: alanine aminotransferase

AST: aspartate aminotransferase 
Ca: calcium

CEOR: Centre of Excellence for Osteoporosis Research

CLIA: competitive chemiluminescence immunoassay

CV: coefficient of variation

FSH: follicular stimulating hormone

Hb: hemoglobin

HbA1c: glycosylated hemoglobin percentage

HDL: high density lipoprotein

HEGC: hyperinsulinemic euglycemic clamp

HOMA-\% $\beta$ : homeostatic model assessment $\beta$-cell secretion

HOMA-IR: homeostatic model assessment of insulin resistance

Hs-CRP: high sensitive C-reactive protein

IQR: interquartile range

KAU: King Abdul-Aziz University

KAUH: King Abdul-Aziz University Hospital

KFMRC: King Fahad Medical Research Centre

LDL: low density lipoprotein

LMP: last menstrual period

Mg: magnesium

PHCC: primary health care center

P04: phosphate

PTH: parathyroid hormone

QUICK-I: quantitative insulin sensitivity check index

T2D: type 2 diabetes mellitus 
T3: thyroxin

T4: triiodothyronine

TFT: thyroid function test

TSH: Thyroid-stimulating hormone

VDBP: vitamin $\mathrm{D}$ binding protein

VitD: vitamin D

VLDL: very low density lipoprotein

WC: waist circumference

WHR: waist-hip ratio

\section{Declarations}

\section{Ethics approval and consent to participate}

Ethical approval of this study was obtained from the Research Ethics Committee, the Faculty of Medicine, KAU (ref no.179-16, Oct/2017). Fully informed, written consent was obtained from the participants.

\section{Consent for publication}

Not applicable.

\section{Availability of data and materials}

The datasets used and/or analysed during the current study are available from the corresponding author on reasonable request.

\section{Competing interests}

The authors declare that they have no competing interests.

\section{Funding}

Joint supervision programme, Department of Physiology, Faculty of Medicine, KAU, Jeddah, Saudi Arabia. The funders had no role in study design, data collection and analysis, decision to publish, or preparation of the manuscript.

\section{Authors' contributions}


SA contributed to the study design and execution, data analysis and manuscript drafting. EA contributed to data analysis, writing review and supervision. MDR contributed to supervision, writing review and editing. MIN contributed to writing review. AC and SL-N contributed to supervision. All authors read and approved the final manuscript.

\section{Acknowledgements}

We are thankful for all the participants of this study.

\section{References}

1. DeLuca HF. Overview of general physiologic features and functions of vitamin D. The American journal of clinical nutrition. 2004;80(6):1689S-96S.

2. Lips $P$, Eekhoff $M$, van Schoor N, Oosterwerff M, de Jongh R, Krul-Poel Y, et al. Vitamin D and type 2 diabetes. The Journal of steroid biochemistry and molecular biology. 2017;173:280-5.

3. Mezza T, Muscogiuri G, Sorice G, Prioletta A, Salomone E, Pontecorvi A, et al. Vitamin D deficiency: a new risk factor for type 2 diabetes. Annals of Nutrition and Metabolism. 2012;61(4):337-48.

4. Grimnes G, Figenschau Y, Almås B, Jorde R. Vitamin D, insulin secretion, sensitivity, and lipids results from a case-control study and a randomized controlled trial using hyperglycemic clamp technique. Diabetes. 2011;60(11):2748-57.

5. Deleskog A, Hilding A, Brismar K, Hamsten A, Efendic S, Östenson C-G. Low serum 25-hydroxyvitamin $D$ level predicts progression to type 2 diabetes in individuals with prediabetes but not with normal glucose tolerance. Diabetologia. 2012;55(6):1668-78.

6. Harris SS. Does vitamin D deficiency contribute to increased rates of cardiovascular disease and type 2 diabetes in African Americans? The American journal of clinical nutrition. 2011;93(5):1175S$8 \mathrm{~S}$.

7. Boucher B. Hypovitaminosis D and risk of type 2 diabetes in British South Asians. Diabetic medicine. 2006;23(3):336-

8. Lee S, Clark SA, Gill RK, Christakos S. 1, 25-Dihydroxyvitamin D3 and pancreatic beta-cell function: vitamin D receptors, gene expression, and insulin secretion. Endocrinology. 1994;134(4):1602-10.

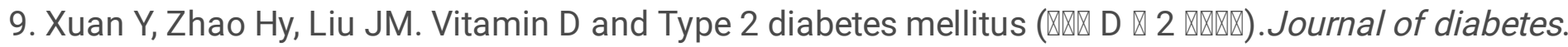
2013;5(3):261-7.

10. Kuchuk NO, van Schoor NM, Pluijm SM, Chines A, Lips P. Vitamin D status, parathyroid function, bone turnover, and BMD in postmenopausal women with osteoporosis: global perspective. Journal of bone and mineral research. 2009;24(4):693-701.

11. Khan $\mathrm{H}$, Kunutsor S, Franco $\mathrm{OH}$, Chowdhury R. Vitamin D, type 2 diabetes and other metabolic outcomes: a systematic review and meta-analysis of prospective studies. Proceedings of the Nutrition Society. 2013;72(01):89-97. 
12. Gulseth HL, Wium C, Angel K, Eriksen EF, Birkeland KI. Effects of vitamin D supplementation on insulin sensitivity and insulin secretion in subjects with type 2 diabetes and vitamin D deficiency: a randomized controlled trial. Diabetes Care. 2017;40(7):872-8.

13. Mitri J, Pittas AG. Vitamin D and diabetes. Endocrinology and Metabolism Clinics. 2014;43(1):20532.

14. Scragg R, Sowers M, Bell C. Serum 25-hydroxyvitamin D, diabetes, and ethnicity in the Third National Health and Nutrition Examination Survey. Diabetes care. 2004;27(12):2813-8.

15. Al-Alyani H, Al-Turki HA, Al-Essa ON, Alani FM, Sadat-Ali M. Vitamin D deficiency in Saudi Arabians: A reality or simply hype: A meta-analysis (2008-2015). Journal of family \& community medicine. 2018;25(1):1.

16. Meo SA. Prevalence and future prediction of type 2 diabetes mellitus in the Kingdom of Saudi Arabia: A systematic review of published studies. JPMA The Journal of the Pakistan Medical Association. 2016;66(6):722-5.

17. Association AD. Diagnosis and classification of diabetes mellitus. Diabetes care. 2010;33(Supplement 1):S62-S9.

18. Zareef TA, Jackson RT, Alkahtani AA. Vitamin D intake among premenopausal women living in Jeddah: food sources and relationship to demographic factors and bone health. Journal of nutrition and metabolism. 2018;2018.

19. Ross AC, Manson JE, Abrams SA, Aloia JF, Brannon PM, Clinton SK, et al. The 2011 report on dietary reference intakes for calcium and vitamin $D$ from the Institute of Medicine: what clinicians need to know. The Journal of Clinical Endocrinology \& Metabolism. 2011;96(1):53-8.

20. Friedewald WT, Levy RI, Fredrickson DS. Estimation of the concentration of low-density lipoprotein cholesterol in plasma, without use of the preparative ultracentrifuge. Clinical chemistry. 1972;18(6):499-502.

21. Wallace TM, Levy JC, Matthews DR. Use and abuse of HOMA modeling. Diabetes care. 2004;27(6):1487-95.

22. Levy JC, Matthews DR, Hermans MP. Correct homeostasis model assessment (HOMA) evaluation uses the computer program. Diabetes care. 1998;21(12):2191-2.

23. Holick MF, editor High prevalence of vitamin D inadequacy and implications for health. Mayo Clinic Proceedings; 2006: Elsevier.

24. Bischoff-Ferrari HA, Giovannucci E, Willett WC, Dietrich T, Dawson-Hughes B. Estimation of optimal serum concentrations of 25-hydroxyvitamin D for multiple health outcomes. The American journal of clinical nutrition. 2006;84(1):18-28.

25. Malabanan A, Veronikis I, Holick M. Redefining vitamin D insufficiency. The Lancet. 1998;351(9105):805-6.

26. Thomas MK, Lloyd-Jones DM, Thadhani RI, Shaw AC, Deraska DJ, Kitch BT, et al. Hypovitaminosis D in medical inpatients. New England Journal of Medicine. 1998;338(12):777-83. 
27. Chapuy M-C, Preziosi P, Maamer M, Arnaud S, Galan P, Hercberg S, et al. Prevalence of vitamin D insufficiency in an adult normal population. Osteoporosis International. 1997;7(5):439-43.

28. Holick MF, Siris ES, Binkley N, Beard MK, Khan A, Katzer JT, et al. Prevalence of vitamin D inadequacy among postmenopausal North American women receiving osteoporosis therapy. The Journal of Clinical Endocrinology \& Metabolism. 2005;90(6):3215-24.

29. Glerup H, Mikkelsen K, Poulsen L, Hass E, Overbeck S, Thomsen J, et al. Commonly recommended daily intake of vitamin $\mathrm{D}$ is not sufficient if sunlight exposure is limited. Journal of internal medicine. 2000;247(2):260-8.

30. Boonen S, Bischoff-Ferrari H, Cooper C, Lips P, Ljunggren O, Meunier P, et al. Addressing the musculoskeletal components of fracture risk with calcium and vitamin D: a review of the evidence. Calcified tissue international. 2006;78(5):257-70.

31. Lips P. Vitamin D deficiency and secondary hyperparathyroidism in the elderly: consequences for bone loss and fractures and therapeutic implications. Endocrine reviews. 2001;22(4):477-501.

32. Bakhtiyarova S, Lesnyak O, Kyznesova N, Blankenstein M, Lips P. Vitamin D status among patients with hip fracture and elderly control subjects in Yekaterinburg, Russia. Osteoporosis international. 2006;17(3):441-6.

33. McKenna MJ. Differences in vitamin D status between countries in young adults and the elderly. The American journal of medicine. 1992;93(1):69-77.

34. Larsen ER, Mosekilde L, Foldspang A. Vitamin D and calcium supplementation prevents osteoporotic fractures in elderly community dwelling residents: a pragmatic population-based 3-year intervention study. Journal of Bone and Mineral Research. 2004;19(3):370-8.

35. Forouhi NG, Luan Ja, Cooper A, Boucher BJ, Wareham NJ. Baseline Serum 25-Hydroxy Vitamin D Is Predictive of Future Glycemic Status and Insulin Resistance. The Medical Research Council Ely Prospective Study 1990-2000. 2008;57(10):2619-25.

36. Hahn S, Haselhorst U, Tan S, Quadbeck B, Schmidt M, Roesler S, et al. Low Serum 25-Hydroxyvitamin D Concentrations are Associated with Insulin Resistance and Obesity in Women with Polycystic Ovary Syndrome. Exp Clin Endocrinol Diabetes. 2006;114(10):577-83.

37. Weiler HA, Lowe J, Krahn J, Leslie WD. Osteocalcin and vitamin D status are inversely associated with homeostatic model assessment of insulin resistance in Canadian Aboriginal and white women: the First Nations Bone Health Study. The Journal of nutritional biochemistry. 2013;24(2):412-8.

38. Dutta D, Maisnam I, Shrivastava A, Sinha A, Ghosh S, Mukhopadhyay P, et al. Serum vitamin-D predicts insulin resistance in individuals with prediabetes. The Indian journal of medical research. 2013;138(6):853.

39. Pittas AG, Lau J, Hu FB, Dawson-Hughes B. The role of vitamin D and calcium in type 2 diabetes. A systematic review and meta-analysis. The Journal of Clinical Endocrinology \& Metabolism. 2007;92(6):2017-29.

40. Almetwazi MS, Noor AO, Almasri DM, Popovici I, Alhawassi T, Alburikan KA, et al. The association of vitamin D deficiency and glucose control among diabetic patients. Saudi Pharmaceutical Journal. 
2017;25(8):1179-83.

41. Sheth JJ, Shah A, Sheth FJ, Trivedi S, Lele M, Shah N, et al. Does vitamin D play a significant role in type 2 diabetes? BMC endocrine disorders. 2015;15(1):5.

42. George P, Pearson E, Witham M. Effect of vitamin D supplementation on glycaemic control and insulin resistance: a systematic review and meta-analysis. Diabetic Medicine. 2012;29(8):e142-e50.

43. Buhary BM, Almohareb O, Aljohani N, Alrajhi S, Elkaissi S, Sherbeeni S, et al. Association of Glycosylated Hemoglobin Levels With Vitamin D Status. Journal of Clinical Medicine Research. 2017;9(12):1013-8.

44. Darraj H, Badedi M, Poore KR, Hummadi A, Khawaji A, Solan Y, et al. Vitamin D deficiency and glycemic control among patients with type 2 diabetes mellitus in Jazan City, Saudi Arabia. Diabetes, metabolic syndrome and obesity: targets and therapy. 2019;12:853.

45. Ahmadieh H, Azar ST, Lakkis N, Arabi A. Hypovitaminosis d in patients with type 2 diabetes mellitus: a relation to disease control and complications. ISRN endocrinology. 2013;2013.

46. Saif-Elnasr M, Ibrahim IM, Alkady MM. Role of Vitamin D on glycemic control and oxidative stress in type 2 diabetes mellitus. Journal of research in medical sciences: the official journal of Isfahan University of Medical Sciences. 2017;22.

47. Wortsman J, Matsuoka LY, Chen TC, Lu Z, Holick MF. Decreased bioavailability of vitamin D in obesity. The American journal of clinical nutrition. 2000;72(3):690-3.

48. Arunabh S, Pollack S, Yeh J, Aloia JF. Body fat content and 25-hydroxyvitamin D levels in healthy women. The Journal of Clinical Endocrinology \& Metabolism. 2003;88(1):157-61.

49. Devaraj S, Jialal G, Cook T, Siegel D, Jialal I. Low vitamin D levels in Northern American adults with the metabolic syndrome. Hormone and metabolic research. 2011;43(01):72-4.

50. Al-Daghri N, Al-Attas O, Alokail M, Alkharfy K, Al-Othman A, Draz H, et al. Hypovitaminosis D associations with adverse metabolic parameters are accentuated in patients with Type 2 diabetes mellitus: a body mass index-independent role of adiponectin? Journal of endocrinological investigation. 2013;36(1):1-6.

51. Nesby-O'Dell S, Scanlon KS, Cogswell ME, Gillespie C, Hollis BW, Looker AC, et al. Hypovitaminosis D prevalence and determinants among African American and white women of reproductive age: third National Health and Nutrition Examination Survey, 1988-1994. The American journal of clinical nutrition. 2002;76(1):187-92.

52. Renzaho AM, Halliday JA, Nowson C. Vitamin D, obesity, and obesity-related chronic disease among ethnic minorities: a systematic review. Nutrition. 2011;27(9):868-79.

53. Fitzpatrick T. Peau et soleil. J Med Esthet. 1975;2:33-4.

\section{Figures}




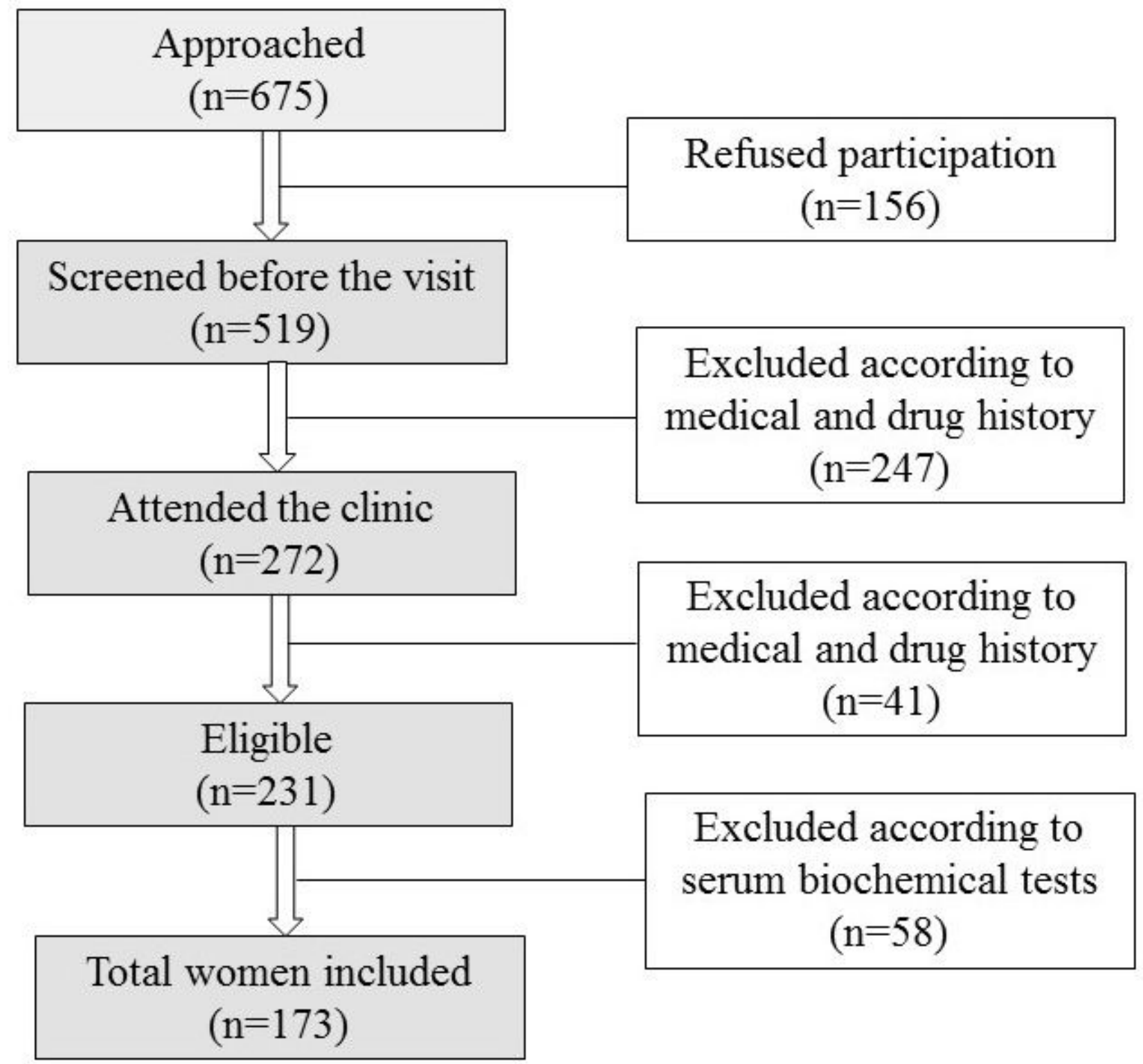

Figure 1

Flow chart of the study postmenopausal participants with T2DM. 
(a)

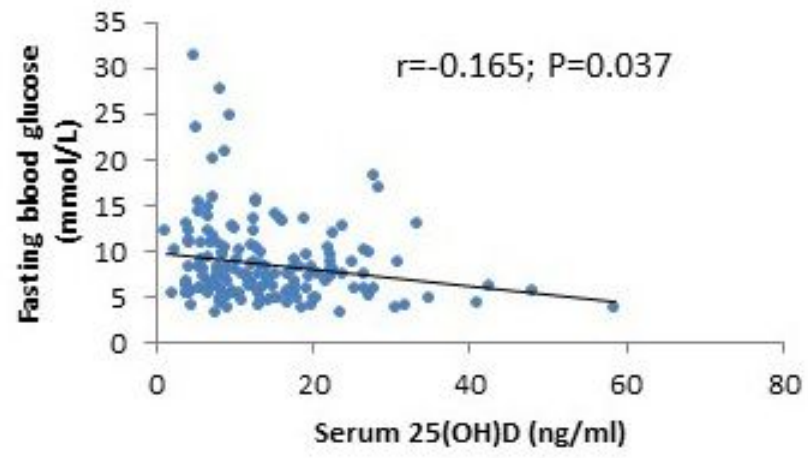

(c)

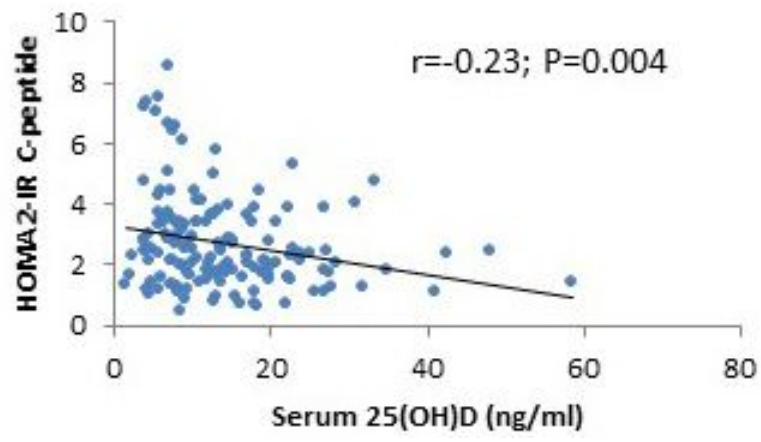

(b)

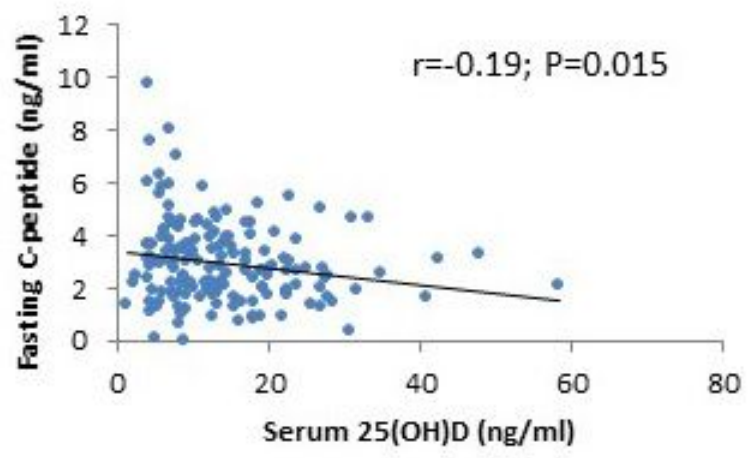

(d)

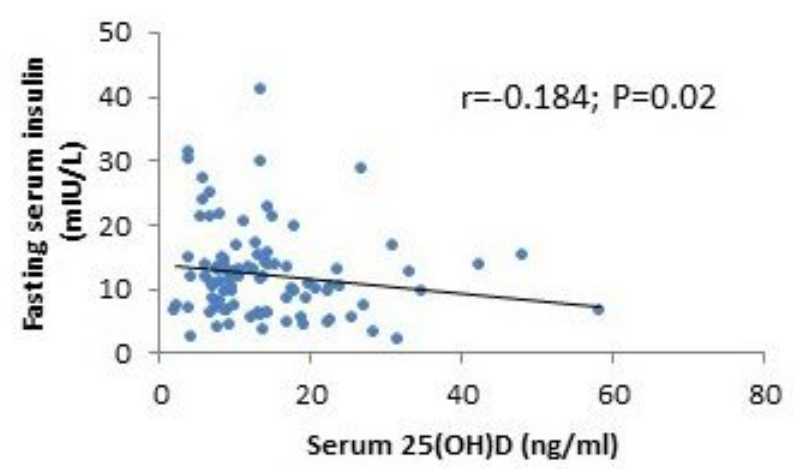

\section{Figure 2}

The relationship between 25(OH)D and glycaemic parameters. (a) The relationship between total $25(\mathrm{OH}) \mathrm{D}$ and fasting glucose ( $\mathrm{n}=173,2$-tailed Spearmen correlation). (b) The relationship between total 25(OH)D and fasting C-peptide ( $n=173,2$-tailed Pearson correlation). (c) The relationship between total 25(OH)D and HOMA2-IR C-peptide ( $n=173$, 2-tailed Spearmen correlation). (d) The relationship between total $25(\mathrm{OH}) \mathrm{D}$ and fasting insulin $(\mathrm{n}=99 *$, 2-tailed Pearson correlation). *Subjects not taking insulin. 